CASE REPORTS

\title{
A case of extreme hypercapnia: implications for the prehospital and accident and emergency department management of acutely dyspnoeic patients
}

\author{
L Urwin, R Murphy, C Robertson, A Pollok
}

Emerg Med J 2004;21:119-120

A 64 year old woman was brought by ambulance to the accident and emergency department. She had been referred by her GP because of increasing dyspnoea, cyanosis, and lethargy over the previous four days. On arrival of the ambulance crew at her home she was noted to be tachycardic and tachypnoeic (respiratory rate $36 / \mathrm{min}$ ) with a GCS of 5 (E 3, M l, V 1). She was given oxygen at 6 l/min via a Duo mask, and transferred to hospital.

The patient arrived at the accident and emergency department 18 minutes later. In transit, there had been a clinical deterioration. The GCS was now 3 and the respiratory rate $4 / \mathrm{min}$. Oxygen saturation, as measured by a pulse oximeter was $99 \%$. The patient was intubated and positive pressure ventilation started. Arterial blood gas measurements taken at the time of intubation were consistent with acute on chronic respiratory failure (fig 1 ).

Further investigations included a chest radiograph, which showed hyperinflation of the lungs and a 12-lead ECG, which showed right axis deviation and right atrial hypertrophy.

Treatment with nebulised bronchodilators, intravenous hydrocortisone, and antibiotics was started empirically with a diagnosis of carbon dioxide narcosis attributable to oxygen therapy in a patient with previously undiagnosed chronic obstructive pulmonary disease. Repeat arterial blood gas analysis was performed seven minutes after intubation and showed: $\mathrm{PaO}_{2} 55.2 \mathrm{kPa}, \mathrm{PaCO}_{2} 21.74 \mathrm{kPa}, \mathrm{H}^{+} 101.0 \mathrm{nmol} / \mathrm{l}$, $\mathrm{HCO}_{3} 40.3 \mathrm{mmol} / \mathrm{l}$.

The patient was transferred to the intensive care unit where mechanical ventilation was continued. Further history revealed that she had smoked 20 cigarettes/day for 40 years but had previously been able to walk as far as her local shops without becoming short of breath. She had not seen her GP nor attended hospital for the previous 16 years.

The following day the patient was much improved. Over a period of two days she was weaned from the ventilator and extubated. She was discharged from hospital to home nine days after admission. At discharge, on room air, arterial blood gas pressures were as follows: $\mathrm{PaO}_{2} 7.52 \mathrm{kPa}, \mathrm{PaCO}_{2} 7.61 \mathrm{kPa}$, $\mathrm{H}^{+} 37.0 \mathrm{nmol} / \mathrm{l}, \mathrm{HCO}_{3} 36.7 \mathrm{mmol} / \mathrm{l}$.

\section{DISCUSSION}

Prehospital, the emergency treatment of patients with dyspnoea must often be undertaken without the benefit of a definitive diagnosis. In the United States between $9 \%$ and $15 \%$ of patients with acute dyspnoea have chronic obstructive pulmonary disease. ${ }^{1}$ In many situations it is possible to identify these patients and modify treatment accordingly. This necessitates some access to the medical history however and on occasion, as in this case, this is not available.

Unfortunately when such a history is unavailable, no out of hospital monitoring technique exists to identify patients with, or at risk of, carbon dioxide retention. Pulse oximetry is used by many ambulance services and can be an extremely useful non-invasive technique to aid the assessment of peripheral oxygen saturation. In situations of poor perfusion, movement and abnormal haemoglobin, however, this technique may not reliably reflect $\mathrm{PaO}_{2}$ values. More importantly, and as shown in our case, there is no definite relation between $\mathrm{SaO}_{2}$ values measured by pulse oximetry and $\mathrm{PaCO}_{2}$ values although it has been shown that the more oxygenated

Acc. No 0001

B.P. $745 \mathrm{mmHg}$

Arterial sample

Patient info

\begin{tabular}{ll}
\multicolumn{2}{c}{$\mathrm{pH} /$ blood gases } \\
Measured at & $37^{\circ} \mathrm{C}$ \\
$\mathrm{cH}$ & $134.0 \mathrm{nmol} / \mathrm{L}$ \\
$\mathrm{pCO}_{2}$ & $31.05 \mathrm{KPa}$ \\
$\mathrm{pO}_{2}$ & $18.0 \mathrm{KPa}$
\end{tabular}

Electolytes

$\begin{array}{lr}\mathrm{Na}^{+} & 131 \mathrm{mmol} / \mathrm{L} \\ \mathrm{K}^{+} & 4.9 \mathrm{mmol} / \mathrm{L} \\ \mathrm{Ca}^{++} & 1.20 \mathrm{mmol} / \mathrm{L}\end{array}$

Calculations

$\begin{array}{lr}\mathrm{HCO}_{3}^{-} & 43.4 \mathrm{mmol} / \mathrm{L} \\ \mathrm{TCO}_{2} & 50.5 \mathrm{mmol} / \mathrm{L} \\ \mathrm{BE}_{\mathrm{b}} & 3.5 \mathrm{mmol} / \mathrm{L} \\ \mathrm{BE}_{\mathrm{Ecf}} & 9.8 \mathrm{mmol} / \mathrm{L} \\ \mathrm{SBC} & 27.5 \mathrm{mmol} / \mathrm{L} \\ \mathrm{sO}_{2} \mathrm{C} & 94.2 \%\end{array}$

Figure 1 Arterial blood gas measurements. 
patients with chronic obstructive pulmonary disease become the higher the incidence of respiratory acidosis. ${ }^{2}$

Clearly, in patients known to have chronic obstructive pulmonary disease it is important to control oxygen therapy to ensure the correction of dangerous levels of hypoxia while minimising the risk of hypercapnia. Despite the fact that our patient deteriorated with the administration of high concentration oxygen, this case should not be used to imply that all dyspnoeic patients should be given lower concentrations of oxygen. In many situations such as acute pulmonary oedema, anaphylaxis, acute asthma, etc, high concentrations of oxygen are essential and even in some patients with acute exacerbations of chronic obstructive pulmonary disease low concentration oxygen will not provide adequate relief of hypoxia. ${ }^{3}$

This case highlights a number of useful learning points:

- Firstly, not all patients with severe chronic obstructive pulmonary disease are identified in the community. Consequently when they become increasingly dyspnoeic there is a risk that inappropriately high concentrations of oxygen may be administered.

- Secondly, the well known risks of inducing hypercapnia and carbon dioxide narcosis cannot reliably be judged by currently available out of hospital monitoring techniques.
- Thirdly, extreme levels of hypercapnia, provided they are treated promptly and appropriately, are compatible with full recovery. To our knowledge, the $\mathrm{PaCO}_{2}$ value of $31.05 \mathrm{kPa}$ with which this patient presented, is the highest recorded in the human literature.

\section{Authors' affiliations}

L Urwin, R Murphy, C Robertson, Department of Accident and Emergency Medicine, Edinburgh Royal Infirmary, Edinburgh, UK A Pollok, Department of Intensive Care Medicine, Edinburgh Royal Infirmary

Correspondence to: MrR Murphy, Department of Accident and Emergency Medicine, The Royal Infirmary of Edinburgh, Old Dalkeith Road, Little France, Edinburgh EH16 4SU, UK;

rossmurphy@doctors.org.uk

Accepted for publication 26 March 2003

\section{REFERENCES}

1 Michelson E, Hollrah S. Evaluation of the patient with shortness of breath: an evidence based approach. Emerg Med Clin North Am 1999;17:221-37.

2 Plant PK, Owen JL, Elliott MW. One year period prevalence study of respiratory acidosis in acute exacerbations of COPD: implications for the provision of non-invasive ventilation and oxygen administration. Thorax 2000;55:550-4.

3 Hutchison DCS, Flenley DC, Donald KW. Controlled oxygen therapy in respiratory failure. BMJ 1964;2:1159-66.

\section{Hypokalaemic thyrotoxic periodic paralysis in an Asian man in the United Kingdom}

\section{R Sinharay}

A large number of ethnic Chinese and other oriental populations are living in the West because of the modern day migration of people. Hypokalaemic periodic paralysis attributable to thyrotoxicosis is a common presentation in an Asian emergency department. It is uncommon in the white communities. There is a difference in the genetic type in the different racial groups. Thyrotoxic features are often masked or absent. Life may be threatened because of severe hypokalaemia and therefore a prompt diagnosis of this condition in the certain ethnic group presenting with weakness and hypokalaemia is essential. Thyroid function studies are mandatory in these cases.

n an Asian population, thyrotoxic periodic paralysis (TPP) is most commonly associated with hypokalaemia. ${ }^{1-4}$ As oriental races are now frequently found in the West, TPP should be included in the differential diagnosis of muscle weakness with hypokalaemia in an emergency department.

\section{CASE REPORT}

In October 2002, a 30 year old Vietnamese of Chinese parentage presented in the early hours of one morning complaining of sudden generalised weakness. The previous day he had worked hard in his "take away" restaurant. He then had a carbohydrate rich meal at around $8 \mathrm{pm}$ and went to bed at around 12 midnight. He had no significant medical or family history.

He had a tachycardia of 100/min and his blood pressure was $119 / 85$. He was fully alert and coherent. His motor power was reduced. He was totally areflexic with both plantars downgoing. He was clinically euthyroid.

His initial serum $\mathrm{K}^{+}$was $1.2 \mathrm{mmol} / \mathrm{l}$ (3.5-4.8) with normal renal function, calcium, glucose, and liver function tests. His serum creatinine phosphokinase concentration was 1099 IU/l (38-148). His blood $\mathrm{pH}$ was 7.44. His $\mathrm{Hb} \%$, white blood cell count, platelets, erythrocyte sedimentation rate, and $\mathrm{C}$ reactive proteins were all normal.

Treatment was started with intravenous administration of $\mathrm{K}^{+}$of $80 \mathrm{mmol}$ over 90 minutes. Once the serum $\mathrm{K}^{+}$reached 4.2 his weakness disappeared. His subsequent serum $\mathrm{K}^{+}$ remained normal. His urine electrolytes in 24 hours' urine were within normal range. His free thyroxine (FT4) level was $73 \mathrm{pmol} / \mathrm{l}(7-17)$, and the TSH level was $0.02 \mathrm{mu} / \mathrm{l}(0.35-$ 2.75). Anti-thyroid peroxidase antibodies were $439 \mathrm{IU} / \mathrm{ml}$ (0.0-35) on admission, which later was increased to $723 \mathrm{IU} /$ ml. Electrocardiogram showed mild tachycardia of 100/min and U-waves in lead II, III, VI-V6.

Ultrasound examination of the thyroid gland showed mild enlargement of the thyroid gland with diffuse parenchymal disease. He was found to have the following human leucocyte antigen (HLA) sub-type: A11, A33; B15, B58; DR3; DQ2, DQ1. 
Table 1 Diagnostic criteria in two most common forms of hypokalaemic periodic paralysis

\begin{tabular}{lll}
\hline & $\begin{array}{l}\text { Thyrotoxic hypokalaemic } \\
\text { periodic paralysis }\end{array}$ & $\begin{array}{l}\text { Hypokalaemic periodic } \\
\text { paralysis (non-familial) }\end{array}$ \\
\hline Episodic & Yes & Yes \\
Acute episodes & Yes & Yes \\
Hypokalaemia & Yes & Yes \\
Family history of paralysis & No & No \\
Large carbohydrate meal & Often & Rare \\
Adrenergic stress & Often & Rare \\
Rapid pulse rate & Yes & Normal \\
Blood pressure & Sometimes high & No \\
Features of thyrotoxicosis & May be absent & No \\
Family history of hyperthyroidism & Some & \\
\hline
\end{tabular}

He was given a carbimazole and $\beta$ blocker combination. In three weeks his FT4 came down to $35 \mathrm{pmol} / \mathrm{l}$. He became biochemically euthyroid by the end of the 14th week. He has remained hypokalaemic weakness free ever since.

\section{DISCUSSION}

This patient has Graves' disease with hypokalaemic paralysis. He recovered quickly with $\mathrm{K}^{+}$replacement. He was given a much larger dose of intravenous $\mathrm{K}^{+}$, instead of the recommended $10 \mathrm{mmol} / \mathrm{h},{ }^{5}$ but fortunately did not show any rebound rise. ${ }^{4}$

Many reported cases of TPP did not have clinical features of thyrotoxicosis. ${ }^{5}$ However, in the Asian patients hyperthyroidism were always obvious, although this has been disputed recently in another study. ${ }^{9}$ A total of $2 \%$ of thyrotoxic patients in China and Japan were reported to have TPP, ${ }^{2}$ but it has also been recognised in the Thai, Vietnamese, Korean, and Malay populations. ${ }^{9}$

TPP is characterised by sudden transient recurrent episodes of painless paralysis usually occurring after heavy exertion or a high carbohydrate meal, followed by a prolonged rest. ${ }^{5}$ The diurnal variation in $\mathrm{K}^{+}$movement where there is nocturnal $\mathrm{K}^{+}$influx into the muscles would explain the tendency for TPP to occur at night. ${ }^{7}$ Deep tendon reflexes are depressed in most patients. ${ }^{5}$ Respiratory muscles are usually, but not always spared. ${ }^{3}$

Recovery can be spontaneous after 3 to 36 hours, but must be speeded up by $\mathrm{K}^{+}$administration. The onset of paralytic attacks in familial periodic paralysis is often during adolescence, but in most published reports, TPP were found to be between the ages of 20 and 40 years. ${ }^{4}$ The male:female ratio in TPP has been estimated to be 20:1. ${ }^{2}$ Recently, a case of TPP with hypokalaemia has been described in a white woman. ${ }^{8}$ Table 1 shows the differential diagnostic criteria for the two most common forms of hypokalaemic periodic paralysis.

Ober reported seven cases of TPP and provided an excellent review of the literature. ${ }^{1}$ It has been postulated that the thyroid hormone directly stimulates Na-K-ATPase dependent $\mathrm{K}^{+}$channel and increases the catecholamine mediated intracellular potassium shift, which is also stimulated by insulin. ${ }^{5}$ Therefore, $\beta$ blockers are a very useful treatment in TPP, associated with hypokalaemia. ${ }^{5}$

Male dominance and the racial difference in TPP with hypokalaemia are very puzzling. ${ }^{8}$ Difference in HLA subtypes in different racial groups have been reported in the past. Japanese (DRW 8), Singapore Chinese (A2BW22, AW19B17), and Hong Kong Chinese (B5, BW46), all have different HLA subtypes. ${ }^{5}$ HLA DRw8 makes the Japanese susceptible to TPP, and yet the same HLA subtype in the white population makes them susceptible to Graves' disease. ${ }^{10}$ A genetic mutation in the control of Na-K-ATPase activity within the same HLA subtype may explain the racial difference. Interestingly, a genetic mutation in TPP has recently been described in the $\mathrm{K}^{+}$-ionic channel gene KCNE3. ${ }^{11}$ Anti-TPO autoantibody is present in $85 \%-95 \%$ of Graves' disease cases, ${ }^{12}$ which is diagnostic of the condition.

This case shows that among the Chinese and other Oriental population living in Britain, hypokalaemic periodic paralysis may be caused by thyrotoxicosis and that thyroid function studies are mandatory in these people.

Correspondence to: Dr R Sinharay, Department of Medicine, Tameside General Hospital, Fountain Street, Ashton Under Lyne, Lancashire OL6 9RW, UK; ranjitsinharay@hotmail.com

Accepted for publication 9 April 2003

\section{REFERENCES}

1 Ober KP. Thyrotoxic periodic paralysis in the United States:report of 7 cases and review of the literature. Medicine 1992;71:109-20.

2 McFadzean AJS, Yeung R. Periodic paralysis complicating thyrotoxicosis in Chinese. BMJ 1967;1:451-5.

3 Ahlawat SK, Sachdev A. Hypokalaemic paralysis. Postgrad Med J 1999;75:193-7.

4 Manoukain MA, Foote JA, Crapo LM. Clinical and metabolic features of thyrotoxic periodic paralysis in 24 episodes. Arch Intern Med 1999; 159:601-6.

5 Salifu MO, Otah K, Carroll HJ, et al. Thyrotoxic hypokalaemic paralysis in a Blackman. Q J Med 2001:94:659-60.

6 Engel AG. Thyroid function and periodic paralysis. Am J Med $1961 ; 30: 327-33$

7 Charness ME, Johns RJ. Hypokalemic periodic paralysis. Johns Hopkins Med J 1978; 143:148-53

8 Dixon AN, Jones R. Thyrotoxic paralysis in a white woman. Postgrad Med J 2002;78:687-8.

9 Goh SH. Thyrotoxic periodic paralysis: reports of seven patients presenting with weakness in an Asian emergency department. Emerg Med J 2002; 19:78-9.

10 Lazarus JH. Hyperthyroidism. Lancet 1997;349:339-43.

11 Da Silva MRD, Cerutti JM, Arnaldi LAT, et al. A mutation in the KCNE3 potassium channel gene is associated with susceptibility to thyrotoxic hypokalaemic periodic paralysis. J Clin Endocrinol Metab 2002;87:4881-4.

12 Kotani T. anti-TPO autoantibodies. Rinsho Byori 1998;46:324-30. 


\title{
Fatal descending necrotising mediastinitis
}

\author{
M Bulut, V Balcı, Ş Akköse, E Armağan
}

Emerg Med J 2004;21:122-123

Descending necrotising mediastinitis rarely develops and this variety of mediastinitis is a highly lethal disease. A case is reported of descending necrotising mediastinitis caused by an odontogenic infection. The importance is emphasised of prompt diagnosis and aggressive surgical mediastinal drainage for the survival of these patients. Most acute mediastinal infections result from oesophageal perforation, either secondary to oesophagoscopy or tumour erosion. Mediastinitis occasionally develops as descending necrotising mediastinitis originating from the complications of cervical or odontogenic infections. Descending necrotising mediastinitis usually has a fulminant course, leading commonly to sepsis and death.

\footnotetext{
A
} 16 year old woman presented to our accident and emergency (A\&E) department complaining of dyspnea, fever, pleuritic chest pain, and swollen throat. Her initial complaints had been a right sided premolar toothache and swollen cheek. Initially she had been treated as an outpatient with parenteral antibiotics for five days in a local medical facility. Upon worsening of her condition (orthopnea, high fever, chest pain), the patient was brought by ambulance to our A\&E department.

On admission, blood pressure was $110 / 70 \mathrm{~mm} \mathrm{Hg}$, pulse rate was 110 beat $/ \mathrm{min}$, respiration rate was $30 \mathrm{breath} / \mathrm{min}$, and her body temperature was $38.9^{\circ} \mathrm{C}$. She appeared to be sick and orthophneic. Physical examination revealed dyspnea, orthopnea, diffuse painless cervical swelling, and decreased breath sounds on the right side of the chest.

Laboratory tests were as follows: white blood cells 17.600/ $\mathrm{mm}^{3}$, haemoglobin $9.6 \mathrm{~g} / \mathrm{dl}$, platelets $481000 / \mathrm{mm}^{3}$. Blood glucose, urea, sodium, potassium, creatinine, and liver function tests were in the normal range.

Chest roentgenogram showed a pneumomediastinum and pneumohydrothorax on the right side. Computed tomography (CT) of the neck and the chest revealed gas bubbles in the neck region, marked inflammation in the mediastinal soft tissues and azygo-oesophageal recessus suggesting a mediastinal abscess and a pleural effusion and pneumothorax on the right side were noted.

In the A\&E department, $1300 \mathrm{ml}$ empyema was drained from the right hemithorax via a chest tube. She was then taken to the operating room and her mediastinal abscess was drained. Intravenous triple antibiotic treatment (ceftazidime $2 \times 1 \mathrm{~g}$ IV, amikacin $1 \times 1 \mathrm{~g} \mathrm{IV}$, and metronidazole $3 \times 500 \mathrm{mg}$ IV) was started. The following day, repeat neck CT was done and revealed a submandibuler abscess, which was also drained. Bacteriological results from samples obtained from the neck, pleura, mediastinum, and blood did not reveal any micro-organism. On hospital day five, another cervicothoracic CT was done and revealed residual pleural empyema and effusion around the major vessels, gas in the soft tissues of the neck and the mediastinum, and a pneumonic infiltration in the posterior lobe of the left lung.
Although she continued to receive intravenous antibiotics, she remained febrile for nine days. At this time her general condition and arterial blood gas pressures deteriorated. She was in significant respiratory distress and she, once again, needed endotracheal intubation. But this was not possible because of massive laryngeal oedema. A tracheostomy was attempted but meanwhile she developed cardiorespiratory arrest. CPR was not successful.

\section{DISCUSSION}

DNM is an uncommon complication of oral and pharyngeal infections ${ }^{1-3}$ spreading caudally through the retropharyngeal space, which is limited by the middle and deep layers of the deep cervical fascia. ${ }^{4}$

The criteria for the diagnosis of DNM were accurately defined by Estrera and colleagues. ${ }^{5}$ These criteria include: $1-$ clinical manifestation of severe oropharyngeal infection (odontogenic, peritonsillar, or retropharyngeal abscesses, Ludwig's angina, or infection secondary to traumatic pharyngeal perforations); 2 -demonstration of characteristic roentgenographic features of mediastinitis; 3-documentation of mediastinitis at operation or postmortem examination, or both; and 4-establishment of relation between oropharyngeal infection and development of the necrotising process in the mediastinum. ${ }^{1356}$ Our patient met all these criteria.

Mediastinitis occurring secondary to descending odontogenic or deep cervical infections is polymicrobial and mixed, caused by a combination of aerobic and anaerobic organisms reflecting the oropharyngeal flora. ${ }^{468}$ Review of the literature shows that although DNM is quite rare, this variety of mediastinitis is a highly lethal disease. The mortality rate of this disease is between $40 \%$ and 50\%. ${ }^{1{ }^{3}}$ Marty-Ane and associates reported that aggressive surgery provides improved results with an $83 \%$ survival rate. ${ }^{134}$

Delayed diagnosis and inadequate drainage are the main causes of the high mortality rate in DNM. ${ }^{579}$ Because of the absence of early clinical or radiological signs, diagnosis is usually delayed. The diagnosis of acute mediastinitis from conventional radiological studies may be difficult. CT is an extremely useful tool in the treatment of cervical infections and the diagnosis of mediastinitis. ${ }^{13710} \mathrm{CT}$ is also extremely useful in the postoperative assessment of the results of surgical drainage and the timing of the re-operations in patients with continued sepsis. ${ }^{1357}$

The mainstay of treatment in patients with DNM is aggressive and adequate surgical drainage of the cervical and mediastinal collections and intravenous broad spectrum antibiotic treatment. ${ }^{13411}$

Mediastinitis secondary to descending odontogenic and deep cervical infections is rare. It should be suspected in patients whose conditions are disproportionately severe to be justified by a trivial pharyngeal or odontogenic infection, or conversely, in whom a mediastinitis develops in the absence of known risk factors, such as previous surgical and diagnostic procedures involving the oesophagus or the upper airways or pharyngeal foreign bodies. At present, CT is a 
valuable tool for early diagnosis of DNM in all patients with deep neck infections to determine the presence of mediastinal involvement.

\section{Authors' affiliations \\ M Bulut, V Balcı, S Akköse, E Armağan, Department of Emergency Medicine, Uludag University Medical School, Bursa, Turkey}

Correspondence to: Dr M Bulut, Department of Emergency Medicine, Uludag University Medical School, 16049 Bursa, Turkey; mbulut94@yahoo.com

Accepted for publication 14 January 2003

\section{REFERENCES}

1 Marty-Ane $\mathrm{CH}$, Berthet JP, Alric P, et al. Management of descending necrotizing mediastinitis: An aggressive treatment for an aggressive disease. Ann Thorac Surg 1999;68:212-17.

2 Brunelli A, Sabbatini A, Catalini G, et al. Descending necrotizing mediastinitis. Surgical drainage and tracheostomy. Arch Otolaryngol Head Neck Surg 1996;122:1326-9.
3 Wheatley MJ, Stirling MC, Kirsh MM, et al. Descending necrotizing mediastinitis: transcervical drainage is not enough. Ann Thorac Surg 1990;49:780-4.

4 Marty-Ane $\mathbf{C H}$, Alauzen $\mathrm{M}$, Alric $\mathrm{P}$, et al. Descending necrotizing mediastinitis. Advantage of mediastinal drainage with thoracotomy. J Thorac Cardiovasc Surg 1994;107:55-61

5 Estrera AS, Landay MJ, Grisham JM, et al. Descending necrotizing mediastinitis. Surg Gynecol Obstet 1983;157:545-52.

6 Berlot G, Tomasini A, Cioffi V, et al. Fatal streptococcus viridans descending mediastinitis: case report and review of the literature. Eur J Emerg Med 1997:4:111-14.

7 Levine TM, Wurster CF, Kresp YP. Mediastinitis occurring as a complication of odontogenic infections. Laryngoscope 1986;96:747-50.

8 Moncada R, Warpeha R, Pickleman J, et al. Mediastinitis from odontogenic and deep cervical infection. Anatomic pathways of propagation. Chest 1978:73:497-500.

9 Morey-Mas M, Caubet-Biayna J, Iriarte-Ortabe Jl. Mediastinitis as a rare complication of an odontogenic infection. Report of a case. Acta Stomatol Belg 1996:93:125-8.

$10 \mathrm{Kim}$ HJ, Park ED, Kim JH, et al. Odontogenic versus nonodontogenic deep neck space infections: CT manifestations. J Comput Assist Tomogr 1997;21:202-8.

11 Payne WS, Larson RH. Acute mediastinitis. Surg Clin North Am 1969:49:999-1009.

\section{Troponin testing: beware pulmonary embolus}

\section{S Conroy, I Kamal, J Cooper}

Serum troponin estimation is widely used in the diagnosis and management of coronary syndromes, but it is possible to be misled by a positive result unless it is put carefully into clinical context. The serum troponin can be positive in pulmonary embolus and carries prognostic significance. A case report is presented and a review of the relevant literature.

$\mathrm{T}$ oponin assays have had a considerable impact in the diagnosis and risk stratification of patients presenting with an acute coronary syndrome. A correctly timed troponin assay has $95 \%-100 \%$ sensitivity and $85 \%-90 \%$ specificity for myocardial damage. ${ }^{1-4}$ However, there are many other causes of a positive troponin test that should be remembered when assessing these patients in order to avoid misdiagnosis.

\section{CASE REPORT}

A 77 year old woman was admitted to hospital with an exacerbation of chronic obstructive pulmonary disease. She had a background of controlled hypertension, paroxysmal atrial fibrillation, and had been a heavy smoker for 30 years. She responded well to initial treatment with antibiotics, bronchodilators, and corticosteroids.

Five days after her admission, she deteriorated acutely with tight central chest pain and dyspnoea. On examination, she was tachycardic (rate 110, sinus rhythm), hypotensive (BP 90/50), but heart sounds were normal and the jugular venous pressure was not elevated. Her ECG showed ST segment depression and T-wave inversion antero-laterally, suggestive of myocardial ischaemia. The chest radiograph showed hyperinflated lung fields but was otherwise unremarkable; her peripheral oxygen saturations were $85 \%$. She was treated with diamorphine, low molecular weight

\section{Joint European and American guidelines on the} diagnosis of myocardial infarction ${ }^{8}$

- A typical rise and fall in troponin or CK-MB

- Plus at least one of the following:

- ischaemic symptoms

- development of pathological Q waves on the ECG

- ECG changes suggestive of ischaemia-ST elevation or ST depression

- Coronary artery intervention, for example, coronary angioplasty

heparin, and aspirin. There was a small rise in creatine kinase (52 to 209 IU/l (normal range 24-195 IU/1)) and the troponin $\mathrm{T} 12$ hours after the pain was significantly raised at $2.1 \mu \mathrm{g} / \mathrm{l} \quad($ normal $<0.01 \mu \mathrm{g} / \mathrm{l})$, consistent with significant myocardial damage. Two days later she was still limited by significant dyspnoea and hypoxia $\left(\mathrm{po}_{2} 8.3\right.$ on air) and the diagnosis of pulmonary embolus was suspected. An echocardiogram was normal in particular demonstrating normal left and right ventricular dimensions and no regional wall motion abnormalities. There was no significant tricuspid regurgitation to permit an estimation of the pulmonary artery pressure. A D-dimer assay was strongly positive at $3872 \mathrm{ng} / \mathrm{ml}$ (normal $<500 \mathrm{ng} / \mathrm{ml}$ ) and a ventilation-perfusion scan showed multiple unmatched defects, indicating a high probability of pulmonary embolus.

\section{DISCUSSION}

An increased serum troponin concentration is found not only in acute coronary syndromes but in several other conditions: myocarditis, stroke, myocardial trauma, post-CABG, chronic renal failure, ischaemic heart failure, ischaemic arrhythmia, 
and pulmonary embolism. ${ }^{5-7}$ The combination of the ischaemic ECG and positive troponin test made pulmonary embolus a difficult initial diagnosis to make in this patient. Indeed, our patient met the revised joint guidelines ${ }^{8}$ for the diagnosis of myocardial infarction. Whether there was concomitant pulmonary embolus and myocardial infarction or pulmonary embolus revealing underlying myocardial ischaemia, is difficult to determine absolutely as further investigation (for example, coronary angiography) was not performed.

Typically, the ECG changes of a pulmonary embolus, if any, are those of either a sinus tachycardia or atrial fibrillation with right heart strain, though many electrocardiographic abnormalities have been reported-rhythm disturbances, axis change, ST-T changes and QT interval prolongation. ${ }^{9-11}$ However, such changes are often transient and the value of the 12-lead ECG in the diagnosis and risk stratification of suspected pulmonary embolus is limited. ${ }^{12}$ ST elevation on the ECG in pulmonary embolus is recognised but an unusual finding. ${ }^{13}$ Given the cardiovascular risk factors present in our patient, it seems probable that there was significant coronary artery disease, which was revealed by the hypoxia and acute cardiac insult of a pulmonary embolus.

A positive troponin test is an important prognostic marker in pulmonary embolus, and predicts right ventricular dilatation and an increased number of segmental perfusion defects on lung scintigraphy. ${ }^{14}$ In a series of 56 patients presenting with pulmonary embolism, $18(32 \%)$ had an increased troponin $\mathrm{T}$ concentration $(>0.1 \mu \mathrm{g} / \mathrm{l})$ taken at 12 hours after presentation. These patients had higher risk of developing complications including in-hospital death (odds ratio 29.6:1, 95\% CI 3.3 to 265.3), prolonged hypotension and cardiogenic shock (odds ratio $11.4: 1,95 \%$ CI 2.1 to 63.4 ), the need for iontropic support (odds ratio 37.6:1, 95\% CI 5.8 to 245.6), and mechanical ventilation (odds ratio $78.8: 1,95 \%$ CI 9.5 to 653.2). ${ }^{15}$ Moreover, after adjustment, an increased troponin $\mathrm{T}$ value was an independent predictor of 30 day mortality in pulmonary embolus (odds ratio $15.2: 1,95 \%$ CI 1.22 to 190.4). It is suggested that troponin estimation may be used to help risk stratify patients with pulmonary embolus who warrant more aggressive treatment.

The recent Joint American and European guidelines ${ }^{8}$ on the diagnosis of myocardial infarction rely heavily upon troponin testing (box). An awareness of other conditions that cause an increased troponin concentration is needed to avoid misdiagnoses. This is particularly the case for patients with pulmonary emboli that may clinically mimic myocardial ischaemia but for which the management is completely different.

\section{Contributors}

Simon Conroy: original idea and literature review. Imad Kamal: advice on content and style. John Cooper: advice on cardiological aspects, style, and content.

Consent for publication was not sought in view of the anonymity of the people concerned.

\section{Authors' affiliations \\ S Conroy, I Kamal, J Cooper, Bedford Hospital, Bedford, UK}

Correspondence to: Dr S Conroy, Bedford Hospital, Kempston Road, Bedford MK42 9DJ, UK; spcon@doctors.org.uk

Accepted for publication 9 January 2003

\section{REFERENCES}

1 Gerhardt W, Ljungdahl L. Detection of myocardial damage by seria measurements of cardiac troponin T, CK MBmass, and TROPT rapid test. Cardiovasc Drugs Ther 1997; 11 (suppl 1):227-40.

2 Gerhardt W, Ljungdahl L. Troponin T. A sensitive and specific diagnostic and prognostic marker of myocardial damage. Clin Chim Acta 1998:272:47-57.

3 Gerhardt W, Liungdahl L, Herbert AK. Troponin-T and CK MB (mass) in early diagnosis of ischemic myocardial injury. The Helsingborg Study, 1992. Clin Biochem 1993;26:231-40.

4 Stubbs $P$, Collinson $P$, Moseley D, et al. Prospective study of the role of cardiac troponin $T$ in patients admitted with unstable angina. BMJ 1996:313:262-4.

5 Douketis JD, Crowther MA, Ginsberg JS. Elevated cardiac troponin levels in patients with submassive pulmonary embolism. Arch Intern Med 2002;162:79-81

6 Pacouret G, Schellenberg F, Hamel E, et al. Troponin I in massive acute pulmonary embolism; results of a prospective series. Presse Med 1998;27:1627.

7 Wong CB, Tang IT, Tiu A. Pulmonary embolism mimicking acute myocardial infarction. Tex Med 1999:95:10.

8 Joint European Society of Cardiology/American College of Cardiology Committee. Myocardial Infarction redefined-a consensus document of the Joint European Society of Cardiology/American College of Cardiology Committee for the redefinition of myocardial infarction. Eur Heart $J$ 2000;21:1502-3.

9 Sreeram N, Cheiriex EC, Smeets JLRM, et al. Value of the 12-lead ECG at hospital admission in the diagnosis of pulmonary embolus. Am J Cardiol, 1994;73;298.

10 Ullman E, Brady WJ, Perron AD, et al. Electrocardiograhic manifestations of pulmonary embolism. Am J Emerg Med 2001;19:514-19.

11 Watanabe T, Kikushima S, Tanno K, et al. Uncommon electrocardiographic changes corresponding to symptoms during recurrent pulmonary embolism as documented by computed tomography scans. Clin Cardiol 1998;21:858-61.

12 Chan TC, Vilke GM, Pollack $M$, et al. Electrocardiographic manifestations: pulmonary embolism. J Emerg Med 2001;21:263-70.

13 Falterman TJ, Martinez JA, Daberkow D, et al. Pulmonary embolism with ST segment elevation in leads V1-V4: case report and review of the literature regarding electrocardiograhic changes in acute pulmonary embolism. J Emerg Med 2001;21:255-61.

14 Meyer T, Binder L, Hruska N, et al. Cardiac troponin I elevation in acute pulmonary embolism is associated with right ventricular dysfunction. J Am Coll Cardiol 2000;36:632-6.

15 Giannitsis E, Muller-Bardorff M, Kurowski V, et al. Independent prognostic value of cardiac troponin $\mathrm{T}$ in patients with confirmed pulmonary embolism. Circulation 2000;102:211-17. 